we needed large camp-fires in the morning and evening. Our camp at Trout Lake could only be reached for six weeks in summer on account of the depth of snow in the fallen timber.

On the whole, it may be remarked of this mountain region, that the astronomical condition, particularly for photographic researches, is unpromising. In only one place were steadiness and transparency combined, and only two nights out of fifteen at the best season of the year were exceptionally fine. The transparency was almost always much more marked than at the sealevel, bui the tremulousness was as great, or even greater, than near New York. It is certain that during more than half the year no work of a delicate character could be done. At the end of August, in sheltered positions, and in good tents, we slept under half a dozen thicknesses of blankel, and only partially undressed. Such a degree of cold distracts the mind and numbs the body. Apparently, therefore, judging from present information, it would not be judicious to move a large telescope and physical observatory into these mountains with the hope of doing continuous work under the most favourable circumstances.

\section{TESTIMONIAL TO MR. DARWIN}

MR. DARWIN has received as a testimonial, on the II occasion of his sixty-ninth birthday, an album, a magnificent folio, bound in velvet and silver, containing the photographs of $\mathbf{1 5}_{54}$ men of science in Germany. The list contains some of the best known and most highly honoured names in Europe. He has likewise received on the same occasion from Holland an album with the photographs of 217 distinguished professors and lovers of science in that country. These gifts are not only highly honourable to Mr. Darwin, but also to the senders as a proof of their generous sympathy with a foreigner; and they further show how widely the great principle of Evolution is now accepted by naturalists.

A German correspondent informs us that the German album bears on the handsome title-page the inscription "Dem Reformator der Naturgeschichte, Charles Darwin."

MICROSCOPICAL INVESTIGATION OF SANDS $A N D$ CLAYS

THE anniversary address of the president, $\mathrm{Mr} . \mathrm{H}$. C. Sorby, F.R.S., at the Royal Microscopical Society on Wednesday, March 7, consisted mainly of an attempt to treat in a systematic manner the application of the microscope to the study of the mineral constituents of sands and clays. The various organisms found in such deposits have been much studied by Ehrenberg and other microscopists, and of late years much attention has been directed to the structure of igneous and other hard rocks, more or less allied to them, which can be cut into thin sections ; but comparatively little attempt has been made to investigate the ultimate constitution of loose sands, muds, and clays.

The scope of this subject, as treated by the author, included the identification of the true mineral nature of the various particles, and the determination of the nature of the rock from which they were originally derived; the chief aim being to trace back the history of the material to the furthest possible extent.

After describing the manner in which the different kinds of deposits should be prepared, examined, and mounted as permanent objects, the author treated at some length on the conditions necessary for satisfactorily seeing the various particles with moderate or very high magnifying powers, and for observing their microscopic structure and optical characters. The particles of clay and the fluid-cavities in the grains of sand are often so minute as to task the power of the microscope to the fullest extent, and some indeed are so small that their perfect definition may perhaps be impossible by any means at our command. It was shown that the condi-

$$
\text { Abstract by the author. }
$$

tions under which many of the objects are visible are such that with highly convergent light and object-glasses of large aperture no dark outline is possible, and therefore they are quite invisible; but become quite distinct when the aperture is reduced to a moderate and appropriate amount. For this reason object-glasses of comparatively small aperture are far the best, since the focal point being further from the front lens, very high powers can be used in cases which are beyond the reach of lenses of large aperture.

The author then went into much detail to show the character of the grains of quartz, mica, and other minerals derived from the decomposition or breaking up of various crystalline rocks, and showed that on the whole there are many characteristic differences between the material derived from granitic and schistose rocks-this difference consisting mainly in the form, internal structure, and optical characters of the various constituent grains; the general conclusion being that a careful study of sands, muds, and clays enables us to form a very satisfactory opinion as to whether they were derived mainly from granitic or schistose rocks, or from a mixture of the two in some approximately definite proportion. It was also shown that the shape of the particles as originally derived from their parent rock is sufficiently definite and characteristic to enable us to form a very good opinion respecting the amount of subsequent mechanical or other change.

Applying those principles to the study of particular typical cases, it was shown that the coarser grained British sandstones have been mainly derived from granite rocks, of a character somewhat intermediate between. those of the Scotch Highlands and Scandinavia. Some of these sandstones consist of grains which have undergone scarcely any wearing, and are as angular as those derived directly from decomposed granite, and are thus totally unlike the blown sand of the deserts, which are worn into perfectly rounded grains.

The finer grained sands are no less angular than the coarse, and have not been derived from the wearing down of larger fragments, but have resulted from the separation of the small from the large grains by the action of currents. Though some fine-grained sand-stones have been mainly derived from granitic rocks, yet, on the whole, the small particles of quartz have more commonly been derived from the breaking up of schistose rocks. Clays and shales consist to a great extent of particles identical in all their characters with those derived from the decomposition of felspars and other minerals which undergo a similar change. As a general rule we meet with many grains of sand even in clays chiefly consisting of extremely minute granules, which can easily be explained by the remarkable manner in which such material, when suspended in water, collects into small compound grains, which subside at a rate quite independent of what would be the velocity of subsidence of the separate particles if they were detached.

The conclusions derived from a study of the characters of the separate grains are confirmed by the occurrence of what may be truly considered to be grains of granite or mica schist. We also in some cases meet with grains sufficiently large to show the characteristic structure of the still more complex rocks of which they are composed. Thin sections of some of the oldest slates in Wales are thus as it were a perfect museum of specimens of the rocks existing at a still earlier period, broken up and worn down into the sands which formed these very ancient slates.

Jn order to establish these various conclusions it would be necessary to enter into a large amount of detail, but perhaps what has been said may suffice to indicate the general line of inquiry, and to show that by making full use of every microscopic means, it is possible to learn many important facts from such very unpromising mate: rials as sands and clays. 